\title{
Legal Metrology and its Development in the Field of Calibration and Verification of Fuel Dispensers and their Application in the Mining Industry
}

\author{
Peter Trebuna ${ }^{1, *}$, Stefan Kral ${ }^{2}$, Tomas Svantner ${ }^{2}$, Marek Kliment ${ }^{3}$, Ladislav Rosocha ${ }^{3}$ \\ Technical University of Kosice, Faculty of Mechanical Engineering, Department of Management, Industrial and Digital Engineering, Park \\ Komenskeho 9, 04001 Kosice \\ Slovak Legal Metrology, Hviezdoslavova 1124/31, 97401 Banská Bystrica \\ Technical University of Kosice, Faculty of Mechanical Engineering, Department of Management, Industrial and Digital Engineering, Park \\ Komenskeho 9, 04001 Kosice
}

\begin{abstract}
The paper deals with metrology and special area of legal metrology, whose task is to ensure consistency and correctness of measurements. The contribution is in addition to definitions and explanations of basic concepts and principles applied in metrology, mainly presented the results of scientific research work in the interdisciplinary field of legal metrology in the Slovak republic. The main content of the paper is a description of calibration equipment for calibration and verification of fuel dispensers, description of the process of research and its application in practice. There are also shown the results of activities in the field of research and development leading to improved measurement accuracy and eliminating subjective influence the measurement. Part of the contribution is to point out the use of calibration equipment in the field of mining in some enterprises in the Slovak Republic. Accurate measurement and determination of fuel consumption in mining operations can help to plan and more accurately determine the cost of operations using with combustion engine machinery. As an example of application of the importance of using metrology equipment we chose the greatest mining and manufacturing magnesite plant in Slovakia, the company SMZ jsc in Jelšava. In this company runs mining with the help of machines driven by combustion engines.
\end{abstract}

Keywords: Metrology, legal metrology, measurement, calibration, fuel dispensers, mining machinery.

\section{Introduction}

Metrology is the science of measurement, allows us to quantify the physical parameters, necessary for objective evaluation of the events and decisions based on facts. The current globalization of markets based on international division of labour required to ensure compatibility of individual parts manufactured in different cooperating countries producing the final product. Global cooperation is possible only on the basis of quality assurance, health and safety of citizens and creates conditions for objectification business transactions.

In the Slovak republic is the basis of metrological infrastructure a law. 142/2000 Journal of Laws of Metrology, which provides basic obligations for achieve that aim and while protecting the public interest, which may be incorrect measurement of the endangered. That law defines the bodies and their powers that the law on metrology applied in practice [1-7].

According JCGM 200: 2012 International Vocabulary of Metrology - Basic and general concepts and associated terms (VIM), 3rd Edition (2008 version with minor corrections) is: 
- Measurement is process of experimentally obtaining one or more quantity values that can reasonably be attributed to a quantity.

- Measurement does not apply to nominal properties.

- Measurement implies comparison of quantities or counting of entities

If the input measured quantities Let be the $X_{1}, X_{2}, \ldots, X_{m}$ and the values of variables (output variables) $Y 1, Y 2, \ldots, Y n$ then the system of equations is a measurement model:

$$
\begin{aligned}
& \mathrm{F} 1\left(\mathrm{X} 1, \ldots, \mathrm{Xm}_{\mathrm{m}} \mathrm{Y1}, \ldots, \mathrm{Yn}\right)=0 \\
& \mathrm{~F} 2(\mathrm{X} 1, \ldots, \mathrm{Xm}, \mathrm{Y} 1, \ldots, \mathrm{Yn})=0 \\
& \ldots \\
& \mathrm{Fr}(\mathrm{X} 1, \ldots, \mathrm{Xm}, \mathrm{Y} 1, \ldots, \mathrm{Yn})=0
\end{aligned}
$$

In the Matrix description:

$X=(X 1, X 2, \ldots, X n) K$ is the vector of input variables,

$Y=(Y 1, Y 2, \ldots, Y n) T$ is the vector of output quantities

$F(X, Y)=[F 1(x, y), \ldots, F(x, y)] T$,

0 is the zero vector.

Measurement result is a set of quantity values being attributed to a measurand together with any other available relevant information. Uncertainty of measurement is non-negative parameter characterizing the dispersion of the quantity values being attributed to a measurand, based on the information used. Measuring instrument is device used for making measurements, alone or in conjunction with one or more supplementary devices. A measuring instrument that can be used alone is a measuring system. A measuring instrument may be an indicating measuring instrument or a material measure [1-7].

Metrology is science of measurement and its application. Metrology includes all theoretical and practical aspects of measurement, whatever the measurement uncertainty and field of application.

Metrology covers three main activities [10]:

1. Defining the basic units of the International System of Units (SI),

2. Realization of the definitions of the quantities represented the basic units of the international SI system - the implementation of primary standard,

3. The transmission values of a given quantities to the etalons of lower orders and measurements - creation chains follow.

Legal metrology is the kind of metrology applied to real life, and uses for ensuring conduct certain frameworks of the social system, the functioning of cooperation in product, service and facilitates the division of labour on the final products of human activity. Legal metrology is not more science and theory of measurement, but it's all the legal and organizational measures, technical resources and activities that seek to guarantee the consistency and correctness of measurements in the national economy. Application of summary knowledge of measurement and legislative laws, technical standards and regulations call for the metrological ensuring. Performance of the tasks of metrological support has always been associated and linked to societal and state interests, so Legal Metrology organizes and usually also provided by the state. In addition to ensuring the quality of products, processes and services are among its traditional role also [10]:

- Consumer protection,

- Uniformity and correctness of measurements,

- Environmental Protection,

- Globalization of production,

- Scientific and technological development.

\section{The role of legal metrology in the process of science and research}

Metrology is part of the society, not only in providing services to the public in accordance with applicable regulations and standards, but also in research and development of new metrological device. Therefore, we consider the role of research in the development of new facilities for the performance of metrology services as part of the obligation to cultivate and develop the level of thinking of people who metrological services provided, but also to come into contact with new technologies, forcing them to reflect on the development of new and better you are currently using. streamline their work performance, ensure better working environment and comfort while process metrology performance is objective [7-13].

In the past period of severalyears, they werewithin the development activities designed tasks related to the objectification of metrological services, where one of the factors reducing the cost of metrological services was also time. Time not only for itself metrological performance, as well as time spent on the preparation of the performance, the actual process of measurement and further processing of measurement data and implementation of the results of work in the database system aimed at archiving and objective data, especially in the case of subsequent irregularities either with direct customer metrological performance, or customer - complainant, who was perhaps as he often says "deceived". Therefore, legal metrology 
and the companies which to ensure research and development of new metrological systems to eliminate such impacts. One such of this company is the Slovak Legal Metrology, which in recent years working on research and development of many new or improved measurement systems [9].

\section{Research and development in the field of calibration and verification of fuel dispensers}

For customer of calibration respectively, verification of the meter is a significant criterion of the temporal aspect, which also translates into economic costs to metrological control. In the stage of distribution of liquid hydrocarbons are fuel dispensers fuel the final link in the chain from production to final distribution to consumers ordinary citizens. Verification of fuel dispensers is a regular metrological performance that results should be evaluated the fuel dispenser, the volume of fuel spillage where the measurement result shall be in accordance with payable legislation $[7,10]$.

The means for carrying out administrative verifications dispenser fuel are different, but today's technologies commonly used in industrial applications including IT technologies have not yet been comprehensively utilized. The aim for research and development in this field it is to create an automated measurement system, whose main objectives are:

- streamlining the metrological performance,

- elimination the subjective influence of the measuring equipment operator,

- automatic data archiving,

- verifiability of the correctness of the implementation of metrological performance.

\section{Legislative or normative requirements}

Dispensers fuel are in accordance with the Act no. 142/2000 Z.z. Metrology and implementing decree Office of Standards Metrology and Testing No. 210/2000 Z.z. on measuring instruments and metrological control of instruments designated. Volumetric flow meters for liquids other than water. Technical requirements and methods of metrological control down the Annex to the Decree Office of Standards, Metrology and Testing No. 210/2000 Z.z. on measuring instruments and metrological control:

- Annex. No. 10 - a volumetric flow meters for liquids other than water,
- Annex. No. 11 - additional devices for the flow measuring instrument other than water,

- Annex. No. 12 - measuring systems for liquids other than water.

For them it is required approval, initial verification and subsequent verification every 24 months. Metrological requirements for measuring instrument and the procedure for the verification described in Annex No.31 to the Decree of the Office of Standards, Metrology and Testing No. 210/2000 Z.z.

OIML issued a recommendation OIML R 117 Dynamic measuring systems for liquids other than water, which defines the requirements for measuring instrument and recommends the procedure for verification. Sources of information are Slovak technical standards: STN 257501 volumetric meters for liquids, STN 997503 a volumetric flow meters for liquids.

\section{The principle of the realized measurement system}

On the basis of current situation and the new scientific and technological knowledge it was elaborated the automated measuring system for calibrating fuel dispensers. The starting point was the method used in the Slovak legal metrology at the verification of these measuring instruments described in the accredited workflow PP-13-07 Verification and calibration of flow meters for liquids other than water - measuring systems. Work procedure is for measuring instruments with a flow of 0.5 pending $200 \mathrm{~L} / \mathrm{min}$, and a maximum permissible error of \pm (0.3 to 3$) \%$ of the volume flow measurement. Dispensing fuel assemblies are calibrated to be verified at the place of application using etalons mobile devices [11].

The solution consists of the design and production of special containers for the calibration system processing requirements for the measurement system and design use the so-called digital artificial eye, which will aim to identify the deduction numerical data of fuel dispensers with subsequent digitization for further processing.

Subsequently was possible to start with a proposal for solution of the whole measurement system including the development of specialized software equipment.

Priority of individual requirements is outlined below in the text [11]:

\section{Reading data from the fuel dispenser:}


- Scans the bar code from the fuel dispenser, prepare technical and software tools to calibrate the fuel dispenser.

- Optically reading with suitable camera of pumped the appropriate quantities of fuel for the values $21,51,20 \mathrm{I}, 100 \mathrm{I}$, including prices for fuel issued for each single measuring separately.

- The data processed into digital form so that they can control control of conversion with price and volume.

- Sensor camera with appropriate lens must be in a safe area at the fuel dispenser fuel

2. Reading the temperature from fuel dispenser out of temperature sensor for each measurement volume.

3. Measure the actual amount of fuel in each calibrated volumetric flask. The tank contains about $200 \mathrm{~mm}$ glass pipette with a scale in the pipette using the contact float level meter to determine the specific amount of fuel uplift for each volumetric flask. Processing of measured data.

4. If the operator cannot see the measuring the fuel dispenser fuel emitted by volume, it is necessary to view it in visual field operator during fuelling.

5. The operator must have access to the measuring hardware before and after refuelling, also there hasn't be a possibility of contact with fuel and instrumentation. It is suitable touch screen with clearly specified procedures for measurement operator.

6. After filling any of measuring cup will be balanced by the value of the volume scanned optically from the dispenser of fuel due to the volume of recorded by the recording the sensor volumetric flask.

7. After converting the temperature compensation is determined by the deviation in the form of tables for each measure volume.

8. This software processes data from measurements after the calibration will be printed directly on the spot reports on verification or calibration. Subsequently, the data will be sent via GMS to a central server in Banska Bystrica, its barcode fuel dispenser.

In collaboration with partners the software has been created application in a dynamic mode where the camera to capture images from the immediate code list of the dispenser tank. This data is processed into digital form and compared with the digital data from the measuring cup in which is the camera position control the air-liquid interface of a transparent glass tube in the fuel measuring cup, where the interface is compared with a mark on the measuring scale. Also, the measured ambient temperature and the temperature of the liquid in the volumetric flask to the necessary temperature compensation. All data are digitized and displayed on a monitor measuring system [1-3].

The biggest problem occurring in digitizing picture emerges is when the lights respectively dial illumination of a fuel dispenser. There are ongoing tests of the measuring system in the laboratory but

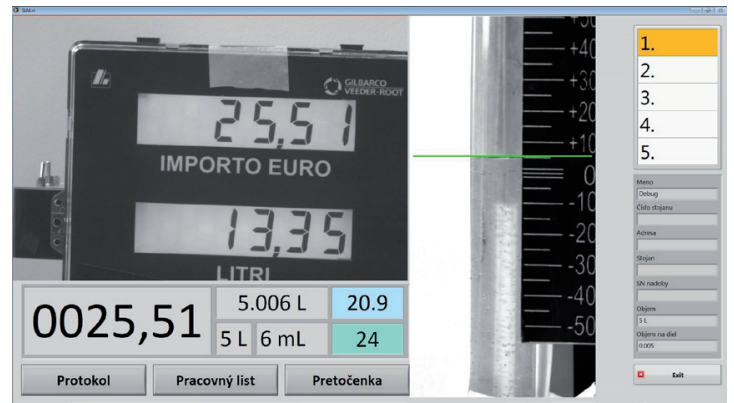

Figure 1: Software system designed for calibration and verification of fuel racks [5]

also in real terms at service stations. It also creates a database of different possible shapes of numbers and displays at petrol stations. After completion of the tests they will create a comprehensive measurement system of calibration for one vehicle. Based on the results of laboratory tests digitization process with optical information of previous stages proceed to the production of specialized measuring vehicles with an automated measuring system for verification of fuel dispensers. It was purchased to a van Citroen Jumper $\mathrm{L} 3 \mathrm{H} 2$, which became the basis of the developed measuring vehicle. After measuring the production of components of the vehicle and the installation of the vehicle have been a major part devoted to development of special software application [11]. Tests were conducted around the device, modify the evaluation algorithm and its software implementation. The measuring vehicle is collecting and measuring tanks, ventilation system and drainage system of fuel at the end of metrology and measuring performance of industrial computer with special software and sample digitizing scanned data (Fig. 1).

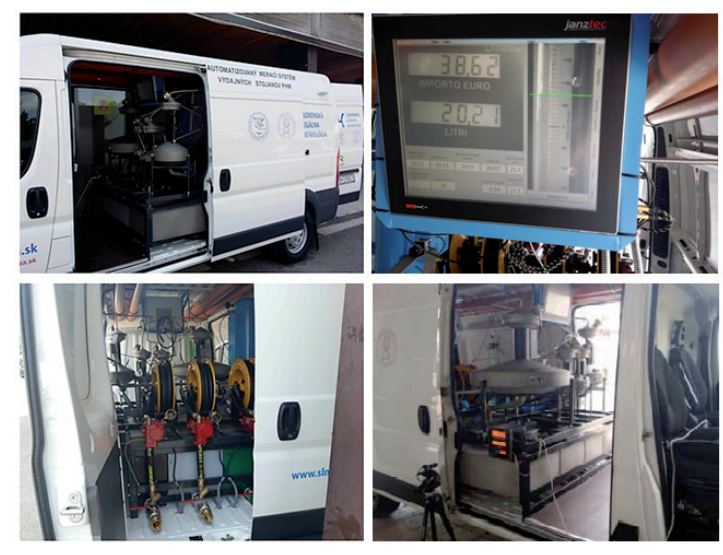

Figure 2: Measuring vehicle and system for calibrating fuel [5] 


\section{The importance of using metrological equipment in mining operations}

As an example of the application of a metrological device for calibration and verification of fuel dispensers, we have chosen mining operations in the Slovak Magnesite Plants in Jelšava. Magnesite plants in Jelšava is the greatest mining and manufacturing magnesite plant in Slovakia. Nowadays, it is a property of joint-stock company and it has gone through over 100 years old history. During the time of its existence the company went through different kinds of transformation process. After breaking-up of the state concern SMZ Košice, on 1.1.1993 there was established the state concern SMZ Jelšava. On 16.2.1994 the plant was registered in the Commercial Register as a joint-stock company. The production program is aimed at the production of loose dead-burned magnesite refractory products, caustic magnesites, slag-forming additives and raw magnesites. After formation of joint stock company, market consolidation and creation of sufficient financial reserves firm re-opened its investing activities. They were mainly aimed at decreasing of production energy intensity, environment and buildings reconstruction. Later in a year 2000 shaft kiln No. XIV was erected. The biggest investment in company modern history was mine opening at level $220 \mathrm{~m}$ in Miková deposit which enabled mining of raw material for next couple decades.

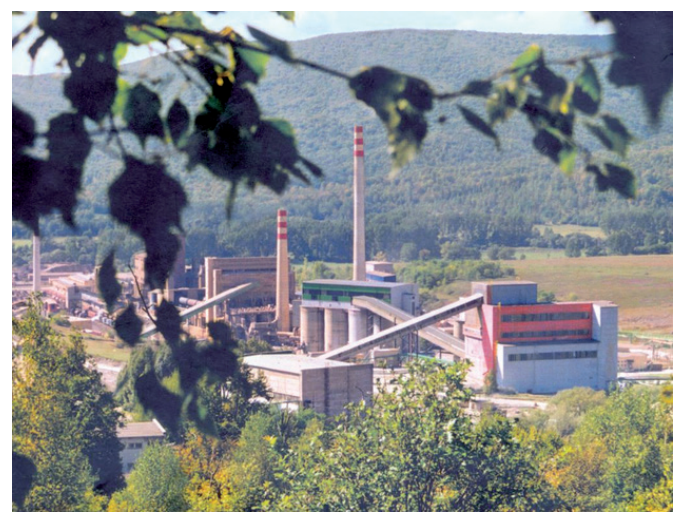

Figure 3: Production plant Slovak Magnesite Plants in Jelšava [4]

SMZ, jsc. Jelšava produces a wide range of loose magnesia, monolithic mixes, slag making additives, a raw magnesite used in an industry like refractory ceramics, metallurgy, building industry, chemistry, environment and agriculture:

- Dead-burnt clinkers - used for production of bricks, monolithic mixes and direct usage in a steel plant aggregates.

- Slag making additives - products used to increase a slag basicity and steel plant aggregates permanent lining protection.

- Basic unshaped monolithic mixes - wide range of products used for erection of new bottoms, hot and cold repairs for electric arc furnaces, convertors, tundish ladles, vacuum aggregates and furnace shells.

- Caustic calcined magnesia - product used as a mineral additive for animal feed production, in chemistry for fertilizers and in environmental field for elimination of acid rains impacts.

- Raw magnesite - used in chemistry for production of chemicals based on magnesium and also in a building industry.

Behavior of the entire production process in the company is illustrated at the figure 4

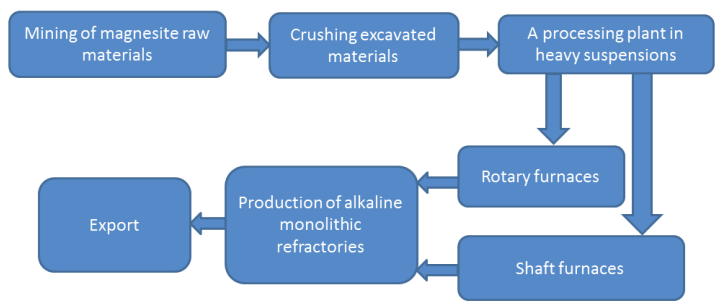

Figure 4: The scheme of the production process SMZ a.s. Jelšava [4]

SMZ, jsc. Jelšava exploits one of the largest magnesite deposits in Europe. The basic mineral form of the mined raw material is magnesium carbonate - magnesite. In the deposit of Dúbravský masív it is found in an isomorphic mixture with dolomite and siderite. Over approximately the last 20 years, the vast majority of raw material has been mined from underneath the earth by means of the overhead stopping method with inter-block pillars with backfilling of the mined areas (Fig.5). This method of mining, due to the elimination of large scale free spaces, increases the safety of the mining procedure; it enables selective separation of mined raw material and, based on defined quality criteria, it also prevents generation of dolomite waste rock piles. On the contrary, $50 \%$ of the backfilling material comes from former waste rock piles originating from the excavation processes performed in the past.

As for hauling equipment, we use electrohydraulic drills, bucket haulers and front scoop loaders. Backfilling is mainly provided by means of motors wheeled haulers complemented with rail transport (Fig.6).

In this area, they are very important factor in the operation of transport in company the fuel and their 
consumption. Each machine with the combustion engine needs fuel for its operations. Especially for heavy mining machines whose engines have a large cylinder capacity to achieve the required performance for heavy work in mining operations. The consumption of such heavy machines ranges in the thousands of litres of fuel per month.

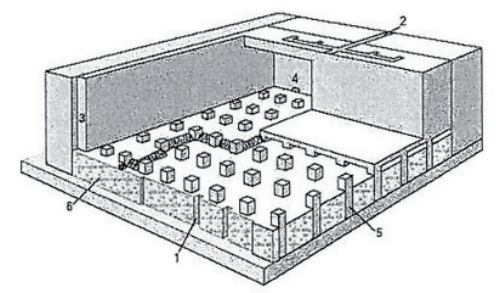

Description 1 - sinking shafts 2 - ventilation shafts 3 - haulage shaft 4 - backfilling shaft 5 - inter-block pillars 6 - backfilling materis

Figure 5: Sketch of the block developed by the overhead stopping method with inter-block pillars [4]
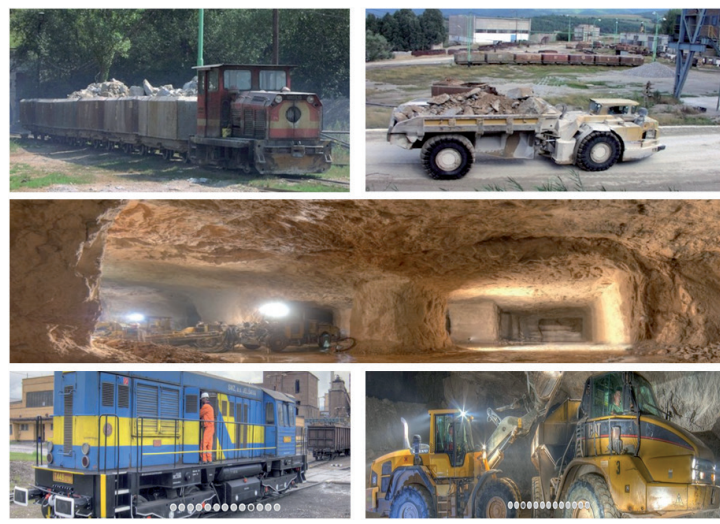

Figure 6: Mining and means of transportation of extracted materials [4]

At present, the company uses fuel dispensers and transport equipment used for years. These devices have been obsolete for years and are not even accurate. For this reason, it is a problem, especially with older machines, to find out the exact consumption of these devices. For this reason, it would be appropriate to calibrate them or upgrade them.

Accurate measurement of fuel consumption will help plan for future production volumes and can serve to increase cost efficiency. To ensure the accuracy of measurement, it is necessary to calibrate the fuel dispensers that are used in the company for refuelling into the machinery needed for the mining and the transport of the material in the production process. For large volumes that are consumed of monthly, it is very important to have accurate fuel consumption data. For each machine, it is possible to determine consumption standards based on the work done and the consumption of fuel. By deal with the optimization and efficiency of the production process, the performance of each machine can be reviewed on the basis of these data. When planning an investment, these data can be used, for example, when think about buying new machines. Based on exact consumption data, it is also possible to consider purchasing more modern, more efficient and economical machines. In this way, it is possible to reduce the cost of fuel and also to ensure a smaller volume of emissions released into the air. Decreasing fuel consumption means increasing the environmental efficiency of the operation.
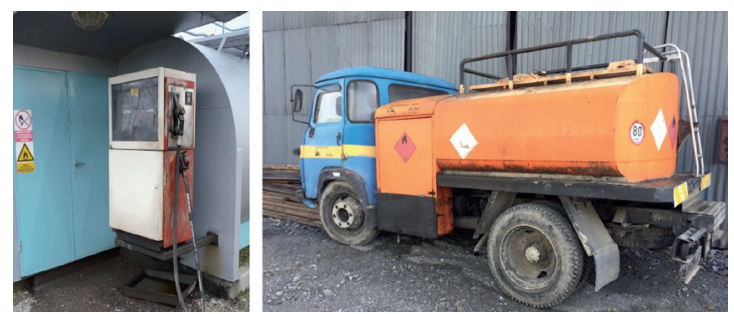

Figure 7 The current state of fuel dispensing equipment in the company [4]

\section{Some of the machines used in the manufacturing process of the company}

In this section are some examples of machines that are used in normal operation in the mining and manufacturing process of an enterprise [4].

When mining is largely used by belt and wheel loader shovel loaders, which ensure loading of the excavated material on the wheeled transporters. These loaders are used both in mine as well as on the surface at the material dumps.

Wheeled transporters are used to export raw materials extracted from the mine to the surface. They are also used to transport material from outside material dumps to a further production process. At these activities also use smaller trucks Tatra 163 Jamal and other trucks.

Additional transport at the area of the company is rail transport, which assists the wheel transporters when moving material between production areas. The company uses several locomotives to tow wagons between product areas or to transfer finished products to the place of export. The place of export is the area of the internal station where the finished products are transhipment to trucks or 
trains that the products deliver to customers around the world. Locomotives also provide transportation of ingredients and raw materials from the import of external raw materials, which are necessary for the production of finished products of the company. These are often several hundred-ton magnesite wagons and other raw materials needed to get the finished products of the company to meet the prescribed parameters.

These and many other machines are used in the plant throughout the manufacturing process. In their activity they consume a large amount of fuel on a monthly basis.

\section{Conclusions}

The overall result is the emergence of a new measurement system for the verification and calibration of fuel dispensers. It is produced by measuring vehicle with an autonomous power source for powering all measuring and powerful vehicle systems, custom software and application with specific optical measuring system (Fig. 2). This solution for the application utility model is currently in issue. New vehicle of metrology and measurement system is an innovative and unique. The result is to increase and improve the metrological performance of the verification of fuel dispensers to service stations, in particular the elimination of subjective influence of the measuring technique for metrology performance. In 2015, at the 22nd International Engineering Trade Fair in Nitra it won the award of metering system - Fair Award EMA. For a given application, method for measuring and metering system a petition for Utility Model has been filed.

The application and use of this modern metrology method can be beneficial to many mining companies as well as other businesses that make extensive use of in-house transport. In the mining industry, heavier machines with a large volume of engines are used to achieve the required work performance. For internal transport it is also used by motorized locomotives. All these machines consume large amounts of fuel. Determining their exact quantity and consumption standards for each machine can play a significant role in future production and cost planning. Calibration of fuel dispensers is important not only at the level of service stations for the public, but also when using in-house service stations.

\section{Acknowledgments}

This article was created by implementation of the grant project VEGA 1/0438/20, KEGA 001TUKE-4/2020, APVV-17-0258 and APVV-19-0418.

\section{References and Notes}

1. Dovica M., Kelemenová T., Henriczyová T.: Súradnicová metrológia. TU Košice, 2012. ISBN 978-80-553-1120-3.

2. Dovica M., Živčák J., Kelemenová T.: Meranie geometrických veličín v strojárstve. GRAFOTLAČ s.r.o. Prešov, 2011. ISBN 978-80-553-0807-4Lehocká, D., Hlavatý, I., Hloch, S. (2016). Rationalization of material flow in production of semitrailer frame for automotive industry. Technical Gazette, Vol. 23, No. 4, 1215-1220, doi:10.17559/TV-20131113100109.

3. Edl M., Lerher T., Rosi B. 2013. „Energy efficiency model for the mini-load automated storage and retrieval systems". International Journal of Advanced Manufacturing Technology, č. 2013, s. 1-19. ISSN: 0268-3768

4. Internal materials $S M Z$ jsc Jelšava, available on the internet (25.06.2018): http://www.smzjelsava.sk/sk

5. Internal materials Slovak Legal Metrology

6. Ižariková G. 2018. Comparative analysis of the industrial production inside the Euro zone, In: Interdisciplinarity in Theory and Practice : the Journal for Presentation of Interdisciplinary Approaches in Various Fields. - Arad (Rumunsko) : Adoram č. 16 (2018), s. 39-46 [print]. - ISSN 2344-2409

7. JCGM 100:2008 GUM 1995 with minor corrections, Evaluation of measurement data - Guide to the expression of uncertainty in measurement, First edition September 2008

8. Kłos S. 2015. Implementation of the AHP method in ERP-based decision support systems for a new product development. Communications in Computer and Information Science. ISSN 1865-0929

9. Monka P. P. 2018. Fundamental Requirements for CAPP Software Design Focusing on Industry 4.0 Specific Features, In: Proceedings of 3rd International Conference on the Industry 4.0 Model for Advanced Manufacturing. - Cham (Švajčiarsko) : Springer s. 146-155 [online]. - ISBN 978-3-31989562-8

10. OIML V1:2000, International Vocabulary of Terms in Legal Metrology (VIML), OIML Secretariat: BUREAU INTERNATIONAL DE MÉTROLOGIE LÉGALE (BIML) 11, RUE TURGOT - 75009 PARIS - FRANCE

11. Palenčár R., Kureková E., Halaj M. 2007. Meranie a metrológia pre manažérov. STU Bratislava 2007. ISBN 978-80-227-27433

12. Saniuk, S., Samolejova, A., Saniuk, A., Lenort, R. 2015. "Benefits and barriers of participation in production 
networks in a metallurgical cluster - research results.", Metalurgija, 54(3), 567-570.

13. Straka M., Lenort R., Khouri S., Feliks J. 2018. Design of large-scale logistics systems using computer simulation hierarchic structure, International Journal of Simulation Modelling, Vol. 17, No. 1, pp. 105-118,

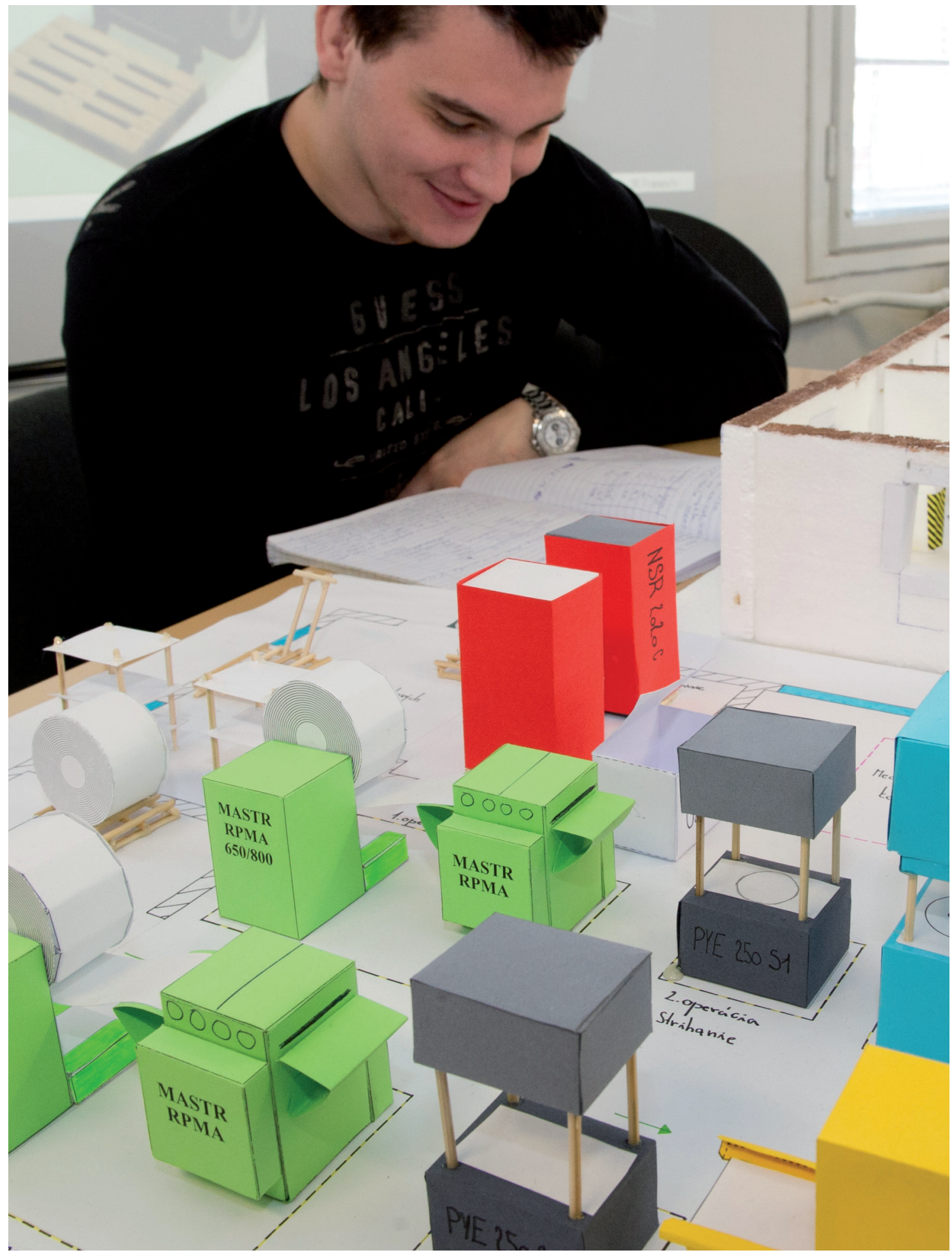

